\title{
Mild and moderate COVID-19 disease does not affect hearing function permanently: a cross-sectional study involving young and middle-aged healthcare givers
}

\author{
Kerem Kökoğlu ${ }^{1}$. Nezaket Tektaş ${ }^{1}$ Fidan Elif Baktir-Okcesiz ${ }^{1}$ - Mehmet Illhan Şahin ${ }^{1}$ (i)
}

Received: 25 January 2021 / Accepted: 12 May 2021 / Published online: 29 June 2021

(c) The Author(s), under exclusive licence to Springer-Verlag GmbH Germany, part of Springer Nature 2021

\begin{abstract}
Purpose To assess the hearing function of patients with mild and moderate COVID-19.

Methods The hospital staffs recovered from COVID-19 were included. The candidates who had an ear disease or progressive hearing loss prior to COVID-19, or having been hospitalised because of severe and critical COVID-19 were excluded. The age, sex, symptoms during COVID-19, and medications received for the disease were noted. The hearing thresholds (HT) of the participants who had an audiogram before having COVID-19 disease were recorded. A pure tone audiometry was conducted to all. The participants were classified into two groups; Group 1: participants who had an audiogram previously, Group 2: participants who didn't have an audiogram previously. The changes of the HTs of the participants in Group 1 were analyzed. The HTs of the participants in Group 2 were documented without any comparison. The HTs of all participants were also analyzed by classifying them into subgroups according to their symptoms during, and medications received for COVID-19.

Results Fifty-four males and 47 females (18-59 years) were included. The participants' HTs in Group $1(n=31)$ did not change significantly at any of the frequencies after having COVID-19 $(p>0.05)$. The pure tone averages of the participants in Group $2(n=70)$ were below $25 \mathrm{~dB}$ and none of the participants reported worsening of their hearing permanently. The differences between the HTs of none of the subgroups were statistically significant $(p>0.05, p>0.05)$.

Conclusions Mild and moderate COVID-19 and its treatments did not affect the hearing function permanently.
\end{abstract}

\section{Introduction}

The coronavirus disease 2019 (COVID-19), which is caused by the severe acute respiratory syndrome coronavirus (SARS-CoV-2), has affected almost 150 million people and killed more than 3 million worldwide, according to the data of the World Health Organisation (WHO) [1].

The virus causes a wide range of clinical spectrum from asymptomatic infection to critical illness [2]. The symptoms of COVID-19 are multisystemic, with the most common symptoms are cough, fatigue, muscle joint pain, fever, shortness of breath, sore throat, vomiting, and diarrhoea. Additionally, neurological manifestations, such as headache, anosmia, ageusia, impaired consciousness, delirium

Mehmet İlhan Şahin

misahin@yahoo.com

1 Department of Otolaryngology, Erciyes University School of Medicine, 38039 Kayseri, Turkey or encephalopathy, agitation, stroke, meningo-encephalitis, depression, and sleep problems, have been observed during the disease [3]. In addition, the presence of neuro-otological symptoms, such as tinnitus and balance disorders in COVID19 patients, has been reported previously [4, 5]. Furthermore, there are publications reporting cases, who experienced sudden sensorineural hearing loss after COVID-19 disease $[6,7]$. However, the hearing functions of a series of patients with COVID-19 have not been previously investigated. This study aimed to assess the hearing function of patients with mild and moderate COVID-19 using audiometric measurements.

\section{Materials and methods}

After ethical committee approval, the hospital staff, who recovered after COVID-19, were invited to participate in the study. Informed consent was obtained form all participants. The exclusion criteria were as follows: history of an 
ear disease or surgery, symptoms such as progessive hearing loss and tinnitus, otalgia, and ear discharge before getting infected, and having been hospitalized because of severe and critical COVID-19. Severe and critical COVID-19 described patients who had severe cardiopulmonary disease and had to be hospitalized due to clinical signs of severe pneumonia or severe acute respiratory infection with a respiratory rate over 30 breaths/minute or oxygen saturation below $92 \%$ on room air. Participants who had pathological findings on otoscopic examination were also excluded.

The age, sex, date of diagnosis confirmed by the polymerase chain reaction (PCR) test, systemic and otolaryngological symptoms during COVID-19, and the medications received for the disease were noted. In addition, the previous hearing thresholds of the participants who had pure tone audiometry before having COVID-19 in our audiology unit were recorded.

A pure tone audiometry test was conducted in a soundproof booth using a clinical audiometer (Madsen Astera, Natus Medical, Taastrup, Denmark) and TDH-39 earphones. The air-conduction hearing thresholds at $125-8000 \mathrm{~Hz}$ and bone-conduction hearing thresholds at $250-4000 \mathrm{~Hz}$ were detected. Pure tone average (PTA) was calculated using the hearing thresholds at four frequencies $(500 \mathrm{~Hz}, 1000 \mathrm{~Hz}$, $2000 \mathrm{~Hz}$, and $4000 \mathrm{~Hz}$ ).

The participants were classified into two groups: Group 1, participants who had an audiogram before COVID-19, and Group 2, participants who did not have an audiogram before COVID-19.
The previous hearing thresholds of the participants in group 1 were compared with their recent hearing thresholds. The hearing thresholds of the participants in group 2 were documented without any comparison. In addition, the hearing thresholds of all participants were analysed by classifying the participants into subgroups according to their symptoms and treatment modalities, apart from Group 1 and Group 2.

SPSS (version 22.0; IBM, New York, USA) and Stata 14.0 (StataCorp LLC, College Station, Texas, USA) software were used for analyses and graphs. A Shapiro-Wilk test was used to test the normality of the data distribution. Normally distributed data are presented as the mean \pm standard deviation (SD). A data measures were not normally distributed, therefore they were presented as medians (range), and the Mann -Whitney U and Wilcoxon signed-rank tests were used for the analysis. Kruskal Wallis test by rank was used to compare more than two groups. A p-value of less than 0.05 was considered statistically significant.

\section{Results}

A total of 101 participants (54 males and 47 females) met the inclusion criteria. The mean age of the participants was $33.86 \pm 8.8$ years ( $18-59$ years).

The systemic symptoms experienced by the participants during COVID-19 disease were myalgia $(n=73)$, arthralgia
Fig. 1 The distribution of the symptoms experienced by the participants during COVID-19 disease

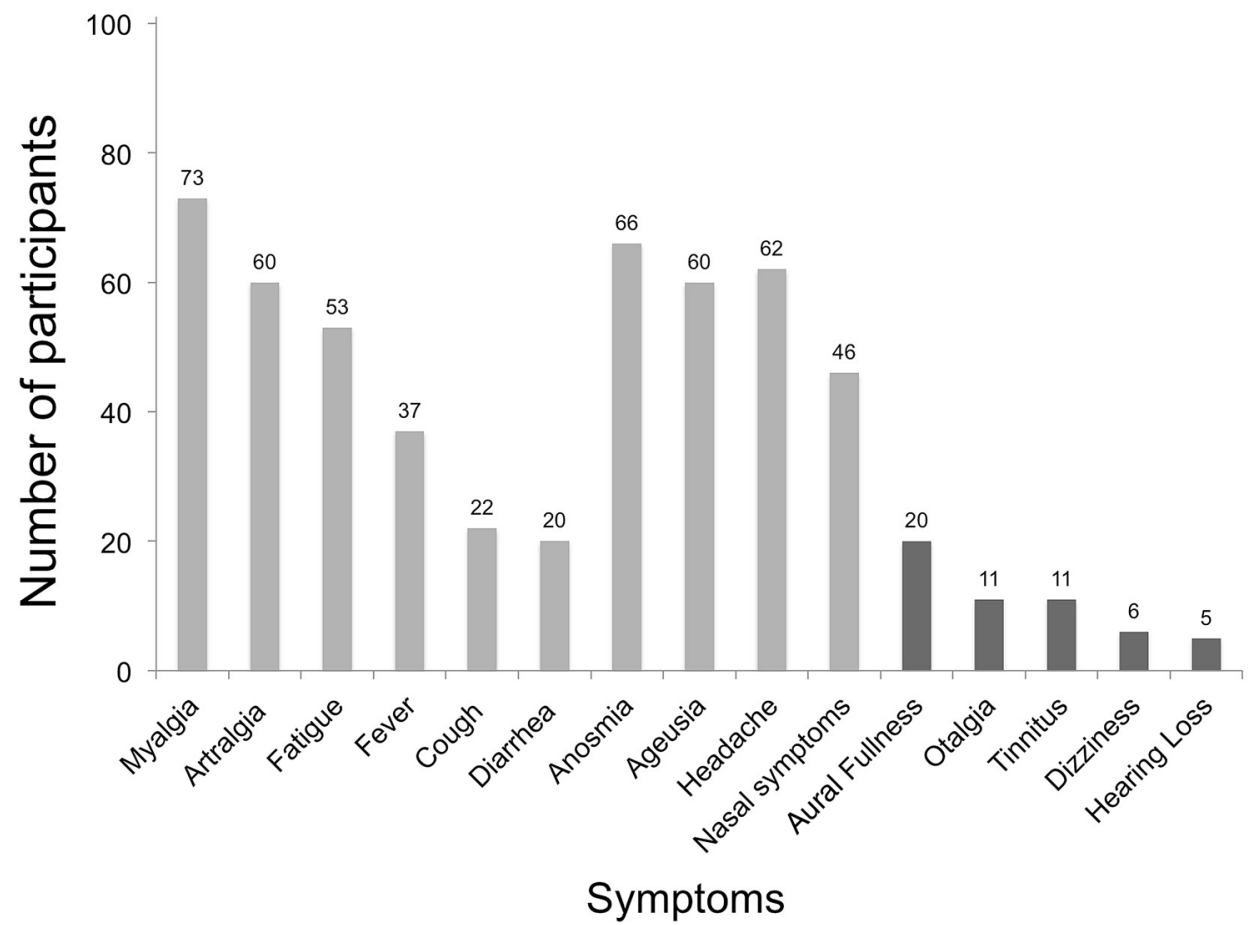


Table 1 Comparison of the pure tone averages of the participants after Covid-19 disease according to the symptoms during COVID-19 disease

\begin{tabular}{|c|c|c|c|c|c|c|c|c|}
\hline & $\begin{array}{l}\text { Fever }(+) \\
(n=37)\end{array}$ & $\begin{array}{l}\text { Fever }(-) \\
(n=64)\end{array}$ & $p$ & $\begin{array}{l}\text { Otological } \\
\text { symptoms } \\
(+)(n=32)\end{array}$ & $\begin{array}{l}\text { Otological } \\
\text { symptoms } \\
(-)(n=69)\end{array}$ & $p$ & $\begin{array}{l}\text { Anosmia } \\
\text { and/or } \\
\text { ageusia }(+) \\
(n=71)\end{array}$ & $\begin{array}{l}\text { Anosmia } \quad p \\
\text { and/or } \\
\text { ageusia }(-) \\
(n=30)\end{array}$ \\
\hline $\begin{array}{l}\text { Right PTA } \\
(\mathrm{dB} H \mathrm{HL}) \\
\text { median } \\
(\min - \\
\max )\end{array}$ & $\begin{array}{l}10(1.25- \\
43.75)\end{array}$ & $10(0-22.5)$ & 0.545 & $10(0-43.75)$ & $\begin{array}{l}8.75 \\
(1.25-22.5)\end{array}$ & 0.194 & $10(0-31.25)$ & $\begin{array}{l}10(1.25-0.497 \\
43.75)\end{array}$ \\
\hline $\begin{array}{l}\text { Left PTA } \\
(\text { dB HL) } \\
\text { median } \\
(\text { min-max })\end{array}$ & $10(3.75-45)$ & $\begin{array}{l}10(-1.25- \\
25)\end{array}$ & 0.983 & $\begin{array}{l}11.25 \\
(-1.25-45)\end{array}$ & $10(0-25)$ & 0.323 & $\begin{array}{l}10(-1.25- \\
30)\end{array}$ & $10.63(0-45) 0.527$ \\
\hline
\end{tabular}

PTA pure tone average $(500 \mathrm{~Hz}-1000 \mathrm{~Hz}-2000 \mathrm{~Hz}-4000 \mathrm{~Hz})$, otological symptoms include aural fullness, otalgia, tinnitus, dizziness, and hearing loss

$(n=60)$, fatigue $(n=53)$, fever $(n=37)$, cough $(n=22)$, and diarrhoea $(n=20)$ (Fig. 1). Fourteen participants had none of those symptoms, and five participants had all of them. When neurological and otolaryngological symptoms were analysed, 71 participants had anosmia and/or ageusia, 55 had both, and 11 only had anosmia. In addition, 62 participants had headaches and 46 participants had nasal symptoms such as nasal obstruction and nasal discharge. The most common otologic symptoms were fullness $(n=20)$, otalgia $(n=11)$, tinnitus $(n=10)$, dizziness $(n=6)$, and hearing loss $(n=5)$. Sixty-nine participants had no otologic symptoms. All participants declared that all otological symptoms had disappeared after recovering from the disease.

The participants received favipiravir (1600 mg loading and $1200 \mathrm{mg}$ in two doses daily for 5 days $)(n=44)$, hydroxychloroquine ( $800 \mathrm{mg}$ loading and $400 \mathrm{mg}$ in two doses daily for 5 days) $(n=23)$, or both $(n=10)$ for COVID19 treatment. Twenty-four participants did not receive any medications.

The mean duration between the audiometric measurements and the end of the participants' quarantine was $55.25 \pm 39.8$ days (10-219 days). Thirty-one of the participants (group 1) had an audiogram before COVID-19. The mean duration between the date of the previous audiogram and COVID-19 diagnosis was $193.75 \pm 199.2$ days (8-840 days).

The participants' hearing thresholds in Group 1 did not change significantly at any of the frequencies after having COVID-19 ( $p>00.05)$ (Fig. 2). The pure tone averages of the participants in Group 2 were below $25 \mathrm{~dB}$. None of the patients complained of worsening of their hearing function permanently.

When the PTAs of the subgroups of participants, who were classified according to the existence of fever, anosmia and/or ageusia, and any of the otologic symptoms during COVID-19, were analysed, the differences between subgroups were not statistically significant $(p>00.05)$ (Table 1).

Comparison of the hearing thresholds between the subgroups of participants classified according to the medications that they received for COVID-19, no significant differences were detected in none of the frequencies $(p>00.05)$ (Table 2).

\section{Discussion}

We investigated the hearing functions of young and middle aged healthcare givers, who recovered from mild and moderate COVID-19, using pure tone audiometry. The hearing thresholds of the participants who had an audiogram previously were also assessed to analyse the possible changes due to the disease. We also analysed the symptoms and treatment modalities of the participants and their relationship with hearing functions. We did not aim to evaluate the hearing function of patients with severe and critical COVID-19. Many of co-factors that could affect the hearing function of these patients; such as being elderly, experiencing hypoxemia during the disease, and various medications they received. Including those patients would disturb the homogeneity of the study group and complicate the finding of a direct relationship between the COVID-19 and hearing function. For these reasons, we formed a homogenous study group that included patients who had only mild and moderate COVID-19.

It is well known that SARS-COV-2 enters the body by binding to the angiotensin-converting enzyme 2 (ACE2) receptor of human cells with its spike (S) protein. ACE2 is a disseminated receptor and is found in several tissues including the lung, nose, heart, kidney, and intestine. After the enterance the virus spreads systemically and causes clinical symptoms of COVID-19 [8]. 


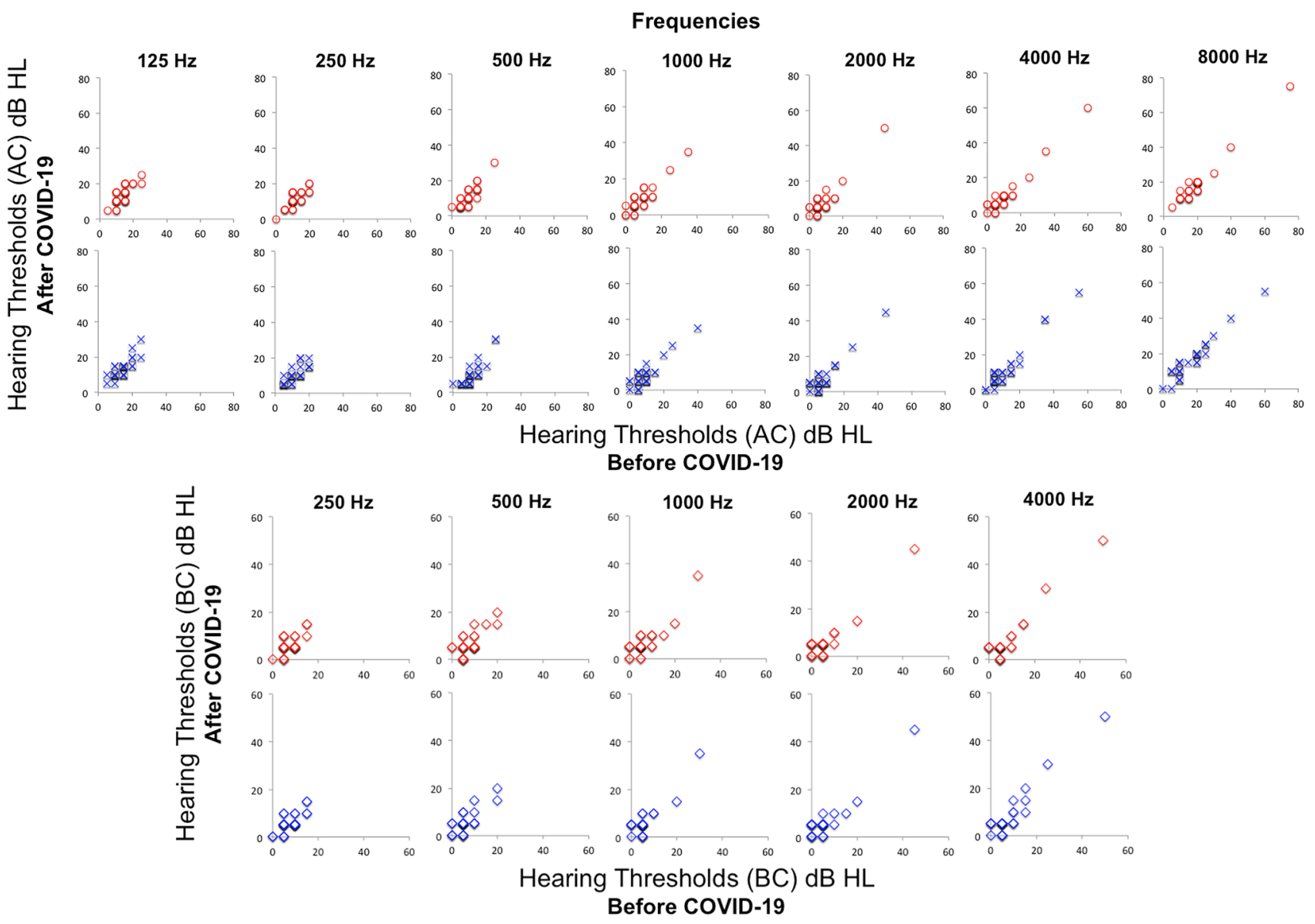

Fig. 2 The hearing thresholds of the participants in Group 2 before and after COVID-19. (AC: Air Conduction, BC: Bone Conduction, dB HL: Decibel Hearing Level) The right ear is indicated with red color and the left ear is indicated with blue color

The disease causes several neurological symptoms, such as headache, anosmia, ageusia, impaired consciousness, delirium or encephalopathy, agitation, stroke, meningoencephalitis, depression, and sleep problems [3]. Astrocytes, oligodendrocytes and neurons encode ACE2 receptors, which have been identified in the olfactory bulb, substantia nigra, ventricles, middle temporal gyrus, and posterior cingulate cortex [9]. Grijalva-Otero [10] has mentioned the potential neurotrophic and neuroinvasive effects of SARSCoV-2 by sampling patients in intensive care units and reported that one third of patients experience neurological symptoms during COVID-19. The mechanism of the central nervous system symptoms due to SARS-CoV-2 virus is not completely understood. One of the potential mechanisms of the entrance of the virus into the central nervous system is through the nose near the olfactory epithelium [11-14].

Therefore, we believe that anosmia and ageusia may be indicators of neuroinvasion and compared the participants, who had experienced these symptoms, with others regarding hearing function. The hearing thresholds of the two subgroups were similar, indicating that anosmia or ageusia did not indicate any disturbance of hearing in COVID-19.

In contrast, regular high fever may be considered an indicator of severe infection [15]. Although none of the participants in this study was hospitalised because of severe or critical COVID-19, 36.6\% of participants declared fever as one of their symptoms and the hearing functions of those were not significantly different from the participants who had not experienced fever during the disease.

While, the presence of SARS-CoV-2 has been demonstrated in the middle ear and mastoid in a cadaver study, it is currently unknown if SARS-CoV-2 affects the cochlea, auditory system, and hearing function [16]. Neuro-otologic symptoms may be seen during COVID-19 disease [4]. Korkmaz et al. [5] reported that the rates of dizziness, tinnitus, true vertigo, and hearing impairment were $31.8 \%$, $11 \%, 6 \%$, and $5.1 \%$ of 116 respectively. There are also case reports announcing the possible role of SARS-CoV-2 in sudden sensorineural hearing loss [6,7]. Nevertheless, it is 


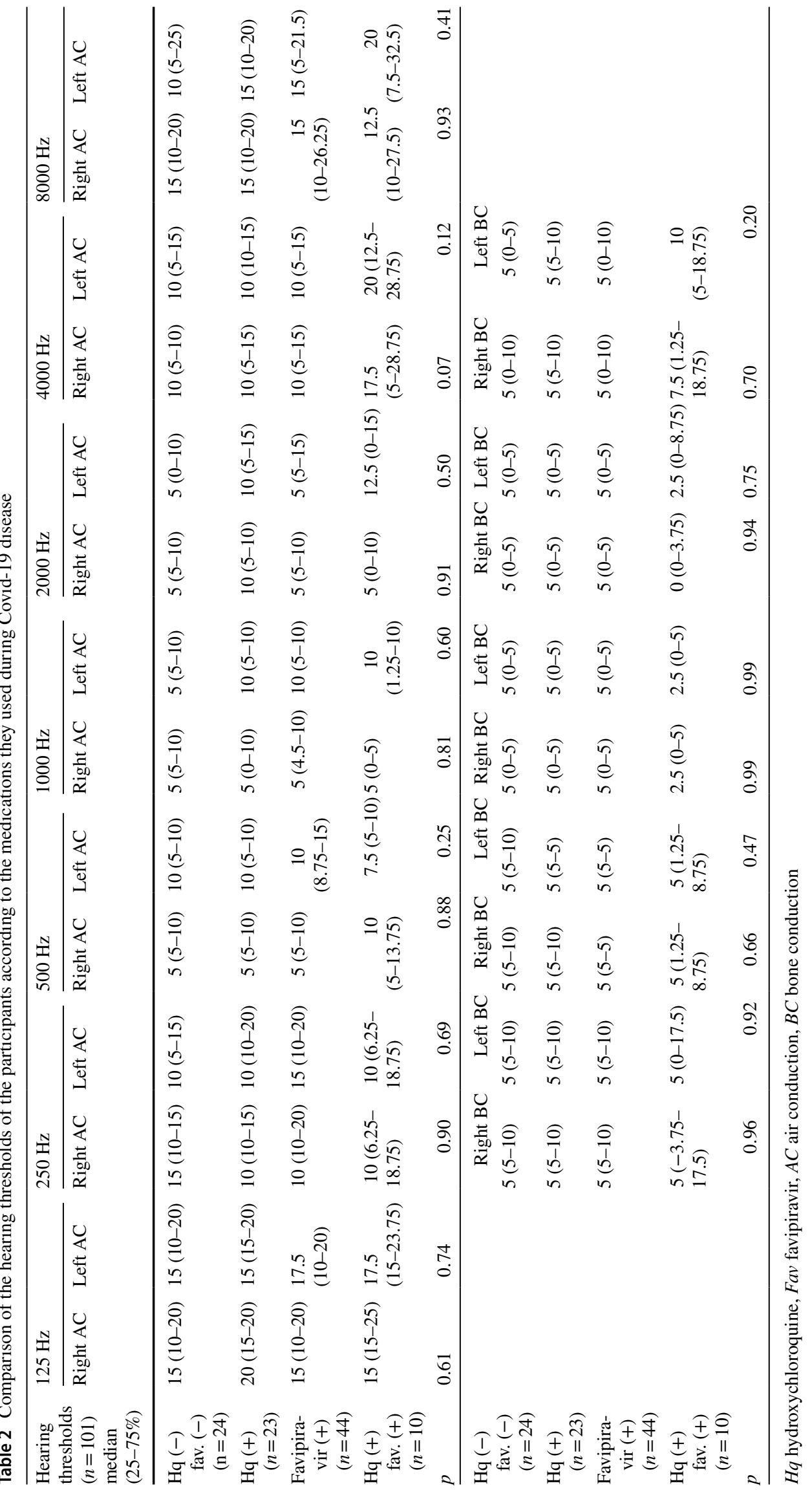


still unclear whether any of the neuro-otologic symptoms caused by the SARS-COV-2 infection become permanent.

We have found that fullness (20\%) was most common neuro-otological symptom; otalgia (11\%), tinnitus (10\%), dizziness (6\%), and hearing loss (5\%) were the following during COVID-19. None of the patients became permanent, and the hearing function was not impaired due to the disease in our sample.

Currently there is no effective treatment defined for COVID-19. Hydroxychloroquine, an anti-malarial, antiinflammatory, and immunomodulating drug, has already been shown to be ineffective in treating COVID-19 [17]. However, it was widely used at the beginning of the outbreak because of the initial reports suggesting its beneficial effects [18]. It has been reported that the use of high-dose hydroxychloroquine may lead to both reversible or permanent deafness [19]. Likewise, favipiravir, which has also been used to treat COVID-19 patients, is considered a potentially ototoxic drug in the literature [20-22].

To answer the question, if the hydroxychloroquine or favipiravir used for COVID-19 treatment affected the hearing of the patients, we classified the participants according to the treatment modialites they had received and compared their hearing data. Our results indicated that neither hydroxychloroquine, nor favipiravir, nor their concomitant use, did not disturb the hearing of the participants.

This is the first study investigating the hearing function, as well as neuro-otologic symptoms of the COVID-19 patients after the disease. We have found that none of the neurotologic symptoms become permanent and the hearing function is not impaired due to mild and moderate COVID19 disease or its treatments.

The limitations of this study include a relatively small group of participants, including only young and middle-aged caregivers, and the heterogeneity of the duration between the end of the disease and the assessment. In addition, the lack of an audiological test battery may be considered as a limitation. However, inviting people, who recovered from COVID-19, for research and applying tests to them was difficult. If the methods of this study are improved and a larger group of participants will be included in further studies, the effects of COVID-19 on hearing function will be clarified more precisely in the future.

\section{Conclusion}

Mild and moderate COVID-19 did not affect the hearing function permanently. Neuro-otological symptoms were not uncommon during the disease, and fortunately, they were not permanent. Furthermore, the medications, favipiravir and hydroxychloroquine which were used for the treatment of COVID-19 in some of the participants in our sample did not affect the hearing function of the participants in these doses in the study.

Funding Own funds.

Availability of data and material Yes.

\section{Declarations}

Conflict of interest The author declares that they have no conflict of interest.

Ethics approval This study was approved by Erciyes University, Ethical Committee of Clinical Researchs, Decision Number: 2020/567.

Consent for publication Yes.

Consent to participate Yes.

\section{References}

1. WHO Coronavirus Disease (COVID-19) Dashboard. Available from: https://covid19.who.int. Accessed 21 Apr 2021

2. McIntosh K. Coronavirus disease 2019 (COVID-19): Clinical features 2020. Available from: https://www.uptodate.com/contents/ coronavirus-disease-2019-covid-19-clinical-features. Accessed 25 Jan 2021

3. Moro E, Priori A, Beghi E, Helbok R, Campiglio L, Bassetti C et al (2020) The international European Academy of Neurology survey on neurological symptoms in patients with COVID-19 infection. Eur J Neurol 27(9):1727-1737

4. Viola P, Ralli M, Pisani D, Malanga D, Sculco D, Messina L et al (2020) Tinnitus and equilibrium disorders in COVID-19 patients: preliminary results. Eur Arch Oto-Rhino-Laryngol. https://doi. org/10.1007/s00405-020-06440

5. Korkmaz MÖ, Eğilmez OK, Özçelik MA, Güven M (2020) Otolaryngological manifestations of hospitalised patients with confirmed COVID-19 infection. Eur Arch Oto-Rhino-Laryngol. https://doi.org/10.1007/s00405-020-06396-8

6. Degen C, Lenarz T, Willenborg K (2020) Acute profound sensorineural hearing loss after COVID 19 pneumonia. Mayo clinic proceedings. Elsevier

7. Kilic O, Kalcioglu MT, Cag Y, Tuysuz O, Pektas E, Caskurlu H et al (2020) Could sudden sensorineural hearing loss be the sole manifestation of COVID-19? an investigation into SARS-COV-2 in the etiology of sudden sensorineural hearing loss. Int J Infect Dis 97:208-211

8. Radzikowska U, Ding M, Tan G, Zhakparov D, Peng Y, Wawrzyniak P et al (2020) Distribution of ACE2, CD147, CD26 and other SARS-CoV-2 associated molecules in tissues and immune cells in health and in asthma, COPD, obesity, hypertension, and COVID-19 risk factors. Allergy 75(11):2829-2845

9. Chen R, Yu J, Wang K, Howard D, French L, Chen Z et al (2020) The spatial and cell-type distribution of SARS-CoV-2 receptor ACE2 in human and mouse brain. BioRxiv. https://doi.org/10. 3389/fneur.2020.573095 
10. Grijalva-Otero I (2020) Role of SARS-CoV-2 neurotropism and neuroinvasion in COVID-19 patients disease severity. Gac Med Mex 156(4):339-343

11. Esmaeil M, Farzane B, Mohammad AS, Tayebeh N, Hamid H, SeyedAhmad S (2021) Olfactory and Gustatory Dysfunctions Due to the Coronavirus Disease (COVID-19) a review of current evidence. Eur Arch Oto-Rhino-Laryngol. https://doi.org/10.1007/ s00405-020-06120-6

12. Lovato A, de Filippis C, Marioni G (2020) Upper airway symptoms in coronavirus disease 2019 COVID 19. Am Journal Otolaryngol. https://doi.org/10.1016/j.amjoto.2020.102474

13. Le Guennec L, Devianne J, Jalin L, Cao A, Galanaud D, Navarro $\mathrm{V}$ et al (2020) Orbitofrontal involvement in a neuroCOVID-19 patient. Epilepsia 61(8):e90-e94

14. Baig AM, Khaleeq A, Ali U, Syeda H (2020) Evidence of the COVID-19 virus targeting the CNS: tissue distribution, host-virus interaction, and proposed neurotropic mechanisms. ACS Chem Neurosci 11(7):995-998

15. Gul MH, Htun ZM, Inayat A (2020) Role of fever and ambient temperature in COVID-19. Expert Rev Respir Med. https://doi. org/10.1080/17476348.2020.1816172

16. Frazier KM, Hooper JE, Mostafa HH, Stewart CM (2020) SARS$\mathrm{CoV}-2$ virus isolated from the mastoid and middle ear: implications for COVID-19 precautions during ear surgery. JAMA Otolaryngol Head Neck Surg 146(10):964-966
17. Mahase E (2020) Hydroxychloroquine for covid-19: the end of the line? BMJ. https://doi.org/10.1136/bmj.m2378

18. Prodromos C, Rumschlag T (2020) Hydroxychloroquine is effective and consistently so used early for Covid-19: a systematic review. New Microb New Infect. https://doi.org/10.1016/j.nmni. 2020.100776

19. Johansen P, Gran J (1998) Ototoxicity due to hydroxychloroquine: report of two cases. Clin Exp Rheumatol 16(4):472-474

20. Cianfrone G, Pentangelo D, Cianfrone F, Mazzei F, Turchetta R, Orlando $\mathrm{M}$ et al (2011) Pharmacological drugs inducing ototoxicity, vestibular symptoms and tinnitus: a reasoned and updated guide. Eur Rev Med Pharmacol Sci 15(6):601-636

21. Elfiky AA (2020) Ribavirin, Remdesivir, Sofosbuvir, Galidesivir, and Tenofovir against SARS-CoV-2 RNA dependent RNA polymerase (RdRp) a molecular docking study. Life Sci. https://doi. org/10.1016/j.lfs.2020.117592

22. Ciorba A, Corazzi V, Skarżyński PH, Skarżyńska MB, Bianchini C, Pelucchi S et al (2020) Don't forget ototoxicity during the SARS-CoV-2 (Covid-19) pandemic! Int J Immunopathol Pharmacol. https://doi.org/10.1177/2058738420941754

Publisher's Note Springer Nature remains neutral with regard to jurisdictional claims in published maps and institutional affiliations. 